\title{
Discharge estimation in compound channels with fixed and mobile bed
}

\author{
GALIP SECKIN $^{1}$, MUSTAFA MAMAK ${ }^{1}$, SERTER ATABAY $^{2}$ and \\ MAZEN OMRAN ${ }^{3}$ \\ ${ }^{1}$ School of Civil Engineering, University of Cukurova, Adana, Turkey \\ ${ }^{2}$ Civil Engineering Department, American University of Sharjah, PO Box 26666, \\ Sharjah, United Arab Emirates \\ ${ }^{3}$ Arup, The Arup Campus, Blythe Gate, Blythe Valley Park, Solihull, West \\ Midlands, B90 8AE, UK \\ e-mail: gseckin@cu.edu.tr; mmamak@cu.edu.tr; satabay@aus.edu; \\ mazen.omran@arup.com
}

MS received 29 August 2008; revised 10 August 2009

\begin{abstract}
Two-dimensional (2-D) formulae for estimating discharge capacity of straight compound channels are reviewed and applied to overbank flows in straight fixed and mobile bed compound channels. The predictive capabilities of these formulae were evaluated using experimental data obtained from the small-scale University of Birmingham channel. Full details of these data and key references may be found at the following www.flowdata.bham.ac.uk (university website). 2-D formulae generally account for bed shear, lateral shear, and secondary flow effects via 3 coefficients $f, \lambda$ and $\Gamma$. In this paper, the secondary flow term $(\Gamma)$ used within the 2-D methods analysed here is ignored in all applications. Two different 2-D formulae almost give practically the same results for the same data when the secondary flow term is ignored. For overall test cases, the value of dimensionless eddy viscosity $\lambda$ used in 2-D formulae was kept at 0.13 as recommended for open channels. 2-D formulae gave good predictions for most of the data sets studied in comparison with the traditional 1-D methods, namely the Single Channel Method (SCM) and the Divided Channel Method (DCM). The accuracy of predictions of 2 -D formulae was increased by calibrating of $\lambda$ value where the calibration was needed. For overall data, the average errors for each method were Lateral Division Methods (LDMs), with $\lambda$ value of $0.13,2.8 \%$, DCM 14.3\% and SCM $-26.8 \%$. The average error was $\mathbf{0} \cdot \mathbf{5} \%$ for LDMs with the calibrated values of $\lambda$.
\end{abstract}

Keywords. Flood and floodworks; river engineering; mathematical modelling.

\section{Introduction}

Compound channels which consist of generally a main river channel and its floodplain are very important for environmental, ecological, and design issues. Therefore, it is essential 
to understand the flow mechanism of rivers in both their inbank and overbank conditions. In a flood event the discharge for a particular river may increase so rapidly that the bankfull condition is breached and the flow passes over onto the floodplain. The structure of the flow then becomes more complex by the momentum transfer between the floodplain and the main channel due to the significant dissimilar velocity distributions in these sub-areas. In this case, the prediction of discharge is more difficult than that when the river is flowing just inbank.

The flow mechanisms in straight compound channels are now well-understood (Knight 1999). In the past two decades, many methods for computing overbank flow have been developed based on either one-dimensional (1-D), or two (2-D) and three-dimensional (3-D) hydrodynamic approaches.

It is well-known that the single channel method (SCM) underestimates the discharge capacity for compound channels. Most divided channel methods (DCM) overestimate the discharge capacity. Nevertheless, SCM and DCM are still widely used in engineering practice, due to their simplicity in use, and can give satisfactory results under certain conditions. See Wright \& Carstens (1970), Wormleaton et al (1982), Prinos \& Townsend (1984), Wormleaton \& Hadjipanos (1985), Myers (1978), Knight \& Hamed (1984), Myers et al (2001), Cassells et al (2001), Seckin (2004) and Atabay (2006) for a comparison of the accuracy of such methods.

Early work by Myers \& Elsawy (1975), Myers (1978), Wormleaton, et al (1982), Knight \& Demetriou (1983), Knight \& Hamed (1984) indicated the importance of taking into account the main channel/floodplain interaction effects which were first recognized and investigated by Sellin (1964) and Zheleznyakov (1971). Ackers (1993) and Bousmar \& Zech (1999) developed 1-D methods; Coherence method (COHM), 1-D Exchange Discharge method (EDM) respectively. Shiono \& Knight (1989), Wark et al (1990), Lambert \& Sellin (1996), Ervine et al (2000), and Prooijen et al (2005) developed 2-D methods; Shiono \& Knight method (SKM), 2-D Lateral Division methods (LDMs), respectively. All these methods take into account momentum transfer due to lateral shear and vorticity at the main channel/floodplain interface.

Seckin (2004) applied four 1-D methods, namely SCM, DCM, COHM and EDM to a major coverage of both experimental and field data obtained from the large-scale UK Flood Channel Facility, small-scale University of Birmingham channel, and a prototype compound river channel (Main River). These data include smooth or rough surfaces for the floodplain proportions, and rigid or mobile surfaces for the main channel section of a compound channel. Seckin (2004) concluded that both EDM and COHM gave better predictions than the SCM and DCM.

It is well-known that three-dimensional (3-D) models require more information and turbulence coefficients and are at present not immediately useful for design purposes due to the calibration requirements. Current study has therefore focused on investigation of the performance of 2-D methods using data from the small-scale University of Birmingham channel. The general validity of 2-D methods has been extended by testing those methods against data sets other than those used in their original formulation.

\section{Theoretical background for the methods}

\subsection{Traditional 1-D methods}

The traditional methods for predicting the discharge conveyed by a compound channel are based on one of the well-known flow formulae, such as the Manning, Chezy or 
Darcy-Weisbach equations, as shown below:

$$
n=R^{2 / 3} S_{0}^{1 / 2} / U_{0} C=U_{0} /\left(R S_{0}\right)^{1 / 2} f=8 g R S_{0} / U_{0}^{2},
$$

where $n, C$, and $f$ are overall resistance coefficients, $U_{0}$ is the section mean velocity, $R$ is the hydraulic radius ( $=A / P$ in which $A$ is flow area and $P$ is wetted perimeter), $S_{0}$ is bed slope and $g$ is gravitational acceleration.

When predicting the discharge in a compound channel using the Single Channel Method (SCM), the whole compound channel section is treated as a single section and the average velocity can be used to predict the discharge as shown in (2):

$$
Q=\left(A R^{2 / 3} S_{0}^{1 / 2}\right) / n=K S_{0}^{1 / 2},
$$

where $K$ is the section conveyance.

When predicting the discharge in a compound channel using the Divided Channel Method (DCM), zonal resistance coefficients have to be calculated. In order to estimate the zonal resistance coefficients, the cross-section of the compound channel is divided into a number of individual sub-sections or zones. The cross-sectional area velocity given in (1) may then be replaced by the sub-section velocity.

The local friction, $f_{b}$, is usually defined in a similar way to the global friction factor, except that the local boundary shear stress, $\tau_{b}$, and the depth-averaged velocity, $U_{d}$, are required instead of the $\tau_{o}$ and $U_{o}$. These 'global', 'zonal' and 'local' resistance coefficients were determined from the following equation. See Knight \& Shiono (1996), and Atabay \& Knight (1999) for further details.

$$
\begin{array}{lll}
\tau_{o}=\left(\frac{f_{o}}{8}\right) \rho U_{o}^{2} ; & \tau_{z}=\left(\frac{f_{z}}{8}\right) \rho U_{z}^{2} ; & \tau_{b}=\left(\frac{f_{b}}{8}\right) \rho U_{b}^{2} \\
\text { (global) } & \text { (zonal) } & \text { (local) }
\end{array}
$$

\subsection{2-D Lateral division methods}

There are several 2-D hydrodynamic methods that have been developed by Shiono \& Knight (1989, 1991), Wark et al (1990), Lambert \& Sellin (1996), Ervine et al (2000), and Prooijen et al (2005). Large-scale Flood Channel Facilities data (FCF), UK have been commonly used to prove the validity of all 2-D methods mentioned above. Here, Shiono \& Knight method $(1989,1991)$ and Ervine et al method (2000) are chosen to investigate the performance of 2-D methods using the data obtained from the small-scale University of Birmingham channel. These 2-D methods are summarized here.

Shiono \& Knight (1989) presented an analytical solution to the Navier-Stokes equation to predict the lateral variation of depth-averaged velocity in compound channels. The NavierStokes equation may be written in the following form for a fluid element in steady uniform flow in which there are both bed generated shear and lateral shear

$$
\rho\left[v \frac{\partial u}{\partial y}+w \frac{\partial w}{\partial z}\right]=\rho \operatorname{gsin} \theta+\frac{\partial \tau_{y x}}{\partial y}+\frac{\partial \tau_{z x}}{\partial z},
$$

(i.e. Secondary flows $=$ weight force + Reynolds stresses(lateral + vertical), where $u, v$ and $w$ are the local velocities in the $x$ (streamwise), $y$ (lateral) and $z$ (vertical) directions respectively; $S_{0}=\sin \theta$, is the bed slope; $\tau_{y x}$ and $\tau_{z x}$ are the Reynolds stresses on planes 
perpendicular to the $y$ and $z$ directions respectively; $\rho$ is the water density; and $g$ is the gravitational acceleration.

Shiono \& Knight (1989) obtained the depth-averaged velocity equation by integrating (3) over the water depth $H$ based on the eddy viscosity approach and, by ignoring the secondary flow contribution, arrived at

$$
\rho g H S_{0}-\frac{1}{8} \rho f U_{d}^{2}\left(1+\frac{1}{s^{2}}\right)^{1 / 2}+\frac{\partial}{\partial y}\left\{\rho \lambda H^{2}\left(\frac{f}{8}\right)^{1 / 2} U_{d} \frac{\partial U_{d}}{\partial y}\right\}=0,
$$

where $U_{d}$ is the depth-averaged mean velocity; $\lambda$ is the dimensionless eddy viscosity; $f$ is the Darcy-Weisbach friction factor and $\mathrm{s}$ is the main channel lateral side slope.

Shiono \& Knight (1989) solved the (4) analytically and obtained the following equation for the case of $H=$ constant in the form

$$
U_{d}=\left[A_{1} e^{\gamma y}+A_{2} e^{-\gamma y}+\frac{8 g S_{0} H}{f}\right]^{1 / 2}
$$

and for linearly varying depth as

$$
U_{d}=\left[A_{3} Y^{\alpha_{1}}+A_{4} Y^{-\alpha_{2}}+\omega Y\right]^{1 / 2},
$$

where $A_{1}, A_{2}, A_{3}$ and $A_{4}$ are unknown constants; and $\gamma, \alpha_{1}, \alpha_{2}$ and $\omega$ are the ancillary terms of (5) and (6) and are given elsewhere by Shiono \& Knight $(1989,1991)$.

Equation (4) is only valid when secondary flows are not considered. However, secondary flows are important in many cases. In such a case, the right-hand side of (4) is not zero (Shiono \& Knight 1989, 1991) and then (4) will be;

$$
\begin{aligned}
& \rho g H S_{0}-\frac{1}{8} \rho f U_{d}^{2}\left(1+\frac{1}{s^{2}}\right)^{1 / 2}+\frac{\partial}{\partial y}\left\{\rho \lambda H^{2}\left(\frac{f}{8}\right)^{1 / 2} U_{d} \frac{\partial U_{d}}{\partial y}\right\} \\
& =\frac{\partial}{\partial y}\left[H(\rho U V)_{d}\right]=\Gamma .
\end{aligned}
$$

Shiono \& Knight (1991) used the approximation in the right hand side of (7) to solve it analytically.

The Shiono \& Knight method (SKM) was originally developed for straight and nearly straight channels. Attempts have been undertaken to use the SKM in modelling non-prismatic and meandering channels (Omran 2005).

The method of Ervine et al (2000) is also similar to the Shiono \& Knight (1991) method and can be applied to both straight and meandering channels. Ervine et al (2000) solved the Navier-Stokes equation (3) analytically in a similar approach used by Shiono \& Knight (1991) and proposed the following formula, by adding the secondary flow contribution, for computing the lateral distribution of depth-averaged velocity;

$$
U_{d}=\sqrt{\left(\frac{8}{\rho f}\left\{\begin{array}{l}
\left.\frac{b^{\prime}}{M+N} \Phi+C_{1} \Phi\left(\begin{array}{l}
\left(L+M-\sqrt{L^{2}+2 L M+M^{2}+4 L N}\right) / 2 L \\
+C_{2} \Phi
\end{array}\right\}\right) \\
\left(L+M+\sqrt{L^{2}+2 L M+M^{2}+4 L N}\right) / 2 L
\end{array}\right)\right.}
$$

where $C_{1}$ and $C_{2}$ are unknown constants; $b^{\prime}, L, M, N$ and $\Phi$ are the ancillary equations of (8) and are given elsewhere by Ervine et al (2000).

For the case of no secondary currents, $K$ which is included within $M$ and $N$ in (8) is equal to zero. 


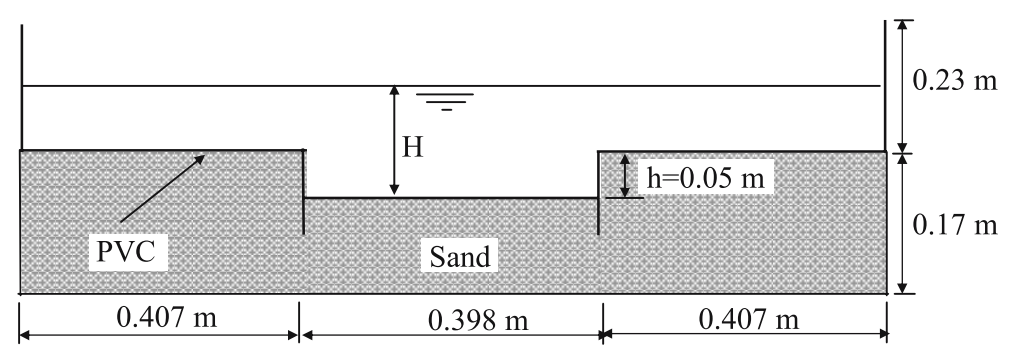

Figure 1. Cross-section of flume at Hydraulic Laboratory of Birmingham University.

\section{Experimental work}

Twelve series of experiments were carried out on the flume of Birmingham University were considered for analysis in this paper. The flume was a non-tilting $22 \mathrm{~m}$ long with a test length of $18 \mathrm{~m}$. The flume was $1213 \mathrm{~mm}$ wide, comprising a $398 \mathrm{~mm}$ wide, $50 \mathrm{~mm}$ deep main channel and two rigid $407.3 \mathrm{~mm}$ wide floodplains, as shown in figure 1 . The bed slope of the flume was set to $2 \cdot 024 \times 10^{-3}$. The flume had three different water circulation systems: two internal ones, which re-circulated water from the downstream end, and one external one, which passed water through the flume to the main laboratory sump. The flow was supplied by $50 \mathrm{~mm}$, $100 \mathrm{~mm}$, and $150 \mathrm{~mm}$ diameter pipelines, and the various discharges were measured by an electro-magnetic flow meter, a venturimeter and a dall tube, respectively. For a given test discharge, the tailgate at the downstream end of the flume was adjusted to produce uniform flow conditions throughout the $18 \mathrm{~m}$ test length. Water surface profiles were measured directly using pointer gauges.

For the smooth main channel and smooth floodplain experiments, both the main channel bed and floodplains were covered with PVC materials (Atabay \& Knight 1999; Atabay 2001; Seckin 2004; Atabay \& Knight 2006).

For either smooth or roughened main channel, and roughened floodplain experiments, $A$ frames of aluminum wire grids, as shown in figure 2 , were placed along the channel at different interval spacings (i.e. $L m=3 \mathrm{~m}, 2 \mathrm{~m}, 1 \mathrm{~m}, 0.5 \mathrm{~m}$, and $0.25 \mathrm{~m}$ ) to create rough surfaces on the main channel and floodplains (Atabay 2001; Seckin 2004; Seckin \& Atabay 2005).

For the mobile bed and smooth floodplain experiments, a uniform sand size of $d_{35}=$ $0.80 \mathrm{~mm}$ was used. (Ayyoubzadeh 1997; Knight et al 1999; Atabay 2001; Atabay \& Seckin 2000; Atabay, Knight et al 2004, 2005).

For the mobile bed and roughened floodplain experiments, $A$-frames of aluminum wire grids were placed along the channel on the floodplains at different interval spacings (i.e. $L_{m}=3 \mathrm{~m}, 1 \mathrm{~m}, 0.5 \mathrm{~m}$, and $0.25 \mathrm{~m}$ ) (Tang \& Knight 2001, 2006).

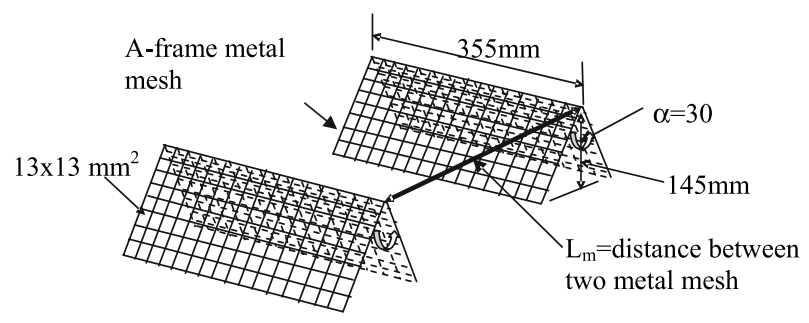

Figure 2. Schematic of metal mesh for the roughness on the floodplain. 
Table 1. Summary of the cross-sectional and roughness parameters for each test case.

\begin{tabular}{|c|c|c|c|c|}
\hline Test case & Cross section & Main channel boundary & Floodplain boundary & Flow description \\
\hline \multicolumn{5}{|c|}{ Fixed boundary tests } \\
\hline F1 & asymmetrical & smooth & smooth & overbank \\
\hline $\mathrm{F} 2$ & symmetrical & smooth & smooth & overbank \\
\hline F3 & symmetrical & smooth & $\operatorname{rough}\left(\lambda_{d}=1 \mathrm{~m}\right)$ & overbank \\
\hline F4 & symmetrical & smooth & $\operatorname{rough}\left(\lambda_{d}=0.5 \mathrm{~m}\right)$ & overbank \\
\hline F5 & symmetrical & $\operatorname{rough}\left(\lambda_{d}=2 \mathrm{~m}\right)$ & $\operatorname{rough}\left(\lambda_{d}=0.5 \mathrm{~m}\right)$ & overbank \\
\hline F6 & symmetrical & $\operatorname{rough}\left(\lambda_{d}=3 \mathrm{~m}\right)$ & $\operatorname{rough}\left(\lambda_{d}=0.25 \mathrm{~m}\right)$ & overbank \\
\hline \multicolumn{5}{|c|}{ Mobile boundary tests } \\
\hline M1 & asymmetrical & mobile & smooth & overbank \\
\hline M2 & symmetrical & mobile & smooth & overbank \\
\hline M3 & symmetrical & mobile & $\operatorname{rough}\left(\lambda_{d}=3 \mathrm{~m}\right)$ & overbank \\
\hline M4 & symmetrical & mobile & $\operatorname{rough}\left(\lambda_{d}=1 \mathrm{~m}\right)$ & overbank \\
\hline M5 & symmetrical & mobile & $\operatorname{rough}\left(\lambda_{d}=0.5 \mathrm{~m}\right)$ & overbank \\
\hline M6 & symmetrical & mobile & $\operatorname{rough}\left(\lambda_{d}=0.25 \mathrm{~m}\right)$ & overbank \\
\hline
\end{tabular}

All the above experimental arrangements are given in table 1 in which $F$ and $M$ denotes fixed and mobile bed experiments, respectively. Full details of these data and key references can be found at www.flowdata.bham.ac.uk.

\subsection{Stage-discharge curves}

Stage-discharge data will be demonstrated graphically in the next sections of this paper and they are also formulated in table 2. Full discussion of these stage-discharge relationships are given in many papers referenced earlier.

Table 2. Stage-discharge relationships for each test case.

\begin{tabular}{|c|c|c|c|c|}
\hline Test No & Discharge range $\left(\mathrm{m}^{3} / \mathrm{s}\right)$ & Depth range $(\mathrm{m})$ & Equation & $R^{2}$ \\
\hline \multicolumn{5}{|c|}{ Fixed boundary cases } \\
\hline $\mathrm{F} 1$ & $0.015-0 \cdot 050$ & $0.061-0 \cdot 106$ & $H=0.4074 Q^{0.4489}$ & 0.9969 \\
\hline $\mathrm{F} 2$ & $0.015-0.055$ & $0.060-0.095$ & $H=0.267 Q^{0 \cdot 3672}$ & 0.9973 \\
\hline F3 & $0.015-0.035$ & $0.062-0 \cdot 104$ & $H=0.8363 Q^{0.6197}$ & 0.9985 \\
\hline F4 & $0.015-0.050$ & $0.065-0.168$ & $H=1.7909 Q^{0.7995}$ & 0.9921 \\
\hline F5 & $0.010-0.035$ & $0.071-0.163$ & $H=1.58 Q^{0.6829}$ & 0.9929 \\
\hline F6 & $0.011-0.027$ & $0 \cdot 071-0 \cdot 141$ & $H=2 \cdot 2867 Q^{0.7698}$ & 0.9971 \\
\hline \multicolumn{5}{|c|}{ Mobile boundary cases } \\
\hline M1 & $0.010-0.027$ & 0.059-0.099 & $H=0.6423 Q^{0.5228}$ & 0.9982 \\
\hline M2 & $0.012-0.045$ & $0.058-0 \cdot 101$ & $H=0.3617 Q^{0.4092}$ & 0.9985 \\
\hline M3 & $0.012-0.028$ & $0.060-0.096$ & $H=0.5781 Q^{0.5072}$ & 0.9942 \\
\hline M4 & $0.012-0.028$ & $0 \cdot 061-0 \cdot 110$ & $H=1.1665 Q^{0.6634}$ & 0.9972 \\
\hline M5 & $0.012-0.028$ & $0.062-0 \cdot 121$ & $H=1.8011 Q^{0 \cdot 7601}$ & 0.9960 \\
\hline M6 & $0.012-0 \cdot 028$ & $0 \cdot 063-0 \cdot 126$ & $H=2 \cdot 2496 Q^{0 \cdot 8022}$ & 0.9963 \\
\hline
\end{tabular}




\subsection{Flow resistance in the main channel and on the floodplains}

In order to estimate the discharge capacity of a compound channel, its cross-section is divided into a number of zones or panels. In this case, particular care needs to be taken over the definition and use of resistance coefficients, as highlighted by Knight (2001). The flow resistance of the main channel and the floodplain proportions of the experimental compound channels were determined from a separate series of experiments or previously published results, as highlighted out by Cassells et al (2001). Herein, for each series of test cases, the main channel and floodplain zonal resistance coefficient, $n_{m c}$ and $n_{f p}$, respectively, is derived from fully low $(H \leq 0.05 \mathrm{~m})$ and high $(H \geq 0.05)$ inbank flow measurements. For the high inbank measurements the main channel of Birmingham University flume was isolated at the bankfull level $(h=0.05 \mathrm{~m})$ using the adjustable side walls on the floodplains (see Ayyoubzadeh 1997; Atabay 2001).

For the smooth main channel and smooth floodplain experiments, both $n_{m c}$ and $n_{f p}$ are equal to 0.0091 measured at bankfull level $(h=0.05 \mathrm{~m})$ as given by Atabay (2001), Atabay \& Knight (2006).

The mobile main channel Manning's $n$ value was taken as 0.015 by Seckin (2004), its measured mean value from inbank flow experiments (see Ayyoubzadeh 1997). Seckin (2004) adopted this constant Manning's $n$ value within EDM and COHM applied to University of Birmingham channel data. The results showed that both EDM and COHM gave large errors up to $19 \%$ for mobile bed experiments.

Atabay \& Knight (2006) highlighted that for mobile beds the alluvial resistance is flow (or depth) dependent. Atabay \& Knight (2006) made three different assumptions concerning the mobile main channel Manning's $n$ :

(i) Single Manning's $n$ value calculated at the bankfull level,

(ii) Variable Manning's $n$ values calculated for wholly inbank flow data $(H \leq 0.05 \mathrm{~m})$, and

(iii) Variable Manning's $n$ values calculated from zonal velocity data $(H>0.05 \mathrm{~m})$.

Atabay \& Knight (2006) adopted these three assumptions within COHM to see which might be the most appropriate for simulating the University of Birmingham flume data and concluded that COHM may be used in mobile bed channels, with $n$ varying with $H$.

Based on the findings of Atabay \& Knight (2006), in this current study, the (9) was adopted to model for the mobile boundary cases instead of constant value of Manning's $n$ to be analysed here:

$$
n_{m c}=1.0862 H^{2}-0.1216 H+0.0176\left(R^{2}=0.7868\right) .
$$

Equation (9) was derived from the work of Ayyoubzadeh (1997) for wholly inbank flow data.

In order to investigate the roughness characteristics of the aluminum wire grid $A$-frames mentioned before, Tang (2002) carried out a series of experiments for fully rough inbank flows, and developed a technique that allows the zonal flow resistance for the aluminum wire grid $A$-frames plus one side wall to be predicted. As a result, Tang (2002) suggested a series of equations giving Manning's $n$-total depth $(H)$ relationships for each space of $L m$ in order to estimate zonal Manning's $n$ coefficients which can be used for overbank flow:

$$
\text { for } \begin{aligned}
L_{m} & =3 \mathrm{~m}: \\
n & =-107 \cdot 21 H^{4}+31.535 H^{3}-3.8985 H^{2}+0.3056 H+0.0098
\end{aligned}
$$




$$
\begin{aligned}
& \text { for } L_{m}=1 \mathrm{~m} \text { : } \\
& n=-80 \cdot 338 H^{4}+36 \cdot 646 H^{3}-6 \cdot 4343 H^{2}+0 \cdot 6083 H+0 \cdot 0101 \\
& \text { for } L_{m}=0.5 \mathrm{~m} \text { : } \\
& n=-62 \cdot 658 H^{4}+36.428 H^{3}-7.9726 H^{2}+0.9017 H+0.0103 \\
& \text { for } L_{m}=0.25 \mathrm{~m} \text { : } \\
& n=-534.79 H^{4}+190 \cdot 73 H^{3}-25 \cdot 253 H^{2}+1.7857 H+0.0099
\end{aligned}
$$

The determination coefficient $\left(R^{2}\right)$ of equations (10)-(13) is equal to 0.9999, 0.9995, 0.9992, and 0.9997 , respectively.

The above equations (10)-(13) were applied to the measured overbank flow depths to be analysed herein, and their average Manning's $n$ values were determined, as shown in table 3 . In table 3 , the values of $n_{f p}$ for both fixed or mobile series of experiments were obtained from the (10)-(13). The values of $n_{m c}$ for roughened main channel cases, tests F5 and F6, were obtained from the measurements at the bankfull level $(h=0.05)$ as 0.021 and 0.018 for $L_{m}=2 \mathrm{~m}$ and $L_{m}=3 \mathrm{~m}$, respectively.

\section{Results and discussion}

After determining the hydraulic resistance of the compound channel sections, the stagedischarge relationship can be estimated and compared with the measured values. In this current work, four different methods, namely, SCM, DCM, Shiono \& Knight (1989, 1991), and the method of Ervine et al (2000), were applied to different sets of small-scale data.

As explained before, both the methods Shiono \& Knight (SKM) and Ervine et al include secondary flow term. In this study the secondary flow term was ignored for all applications. In this case, 2-D methods required only two parameter, hydraulic resistance coefficient, $f$,

Table 3. Manning's $n$ roughness coefficients used for each method.

\begin{tabular}{lcc}
\hline & \multicolumn{2}{c}{ Low and High inbank measurements } \\
\cline { 2 - 3 } Test No. & $n_{m c}$ & $n_{f p}$ \\
\hline F1 & 0.0091 & 0.0091 \\
F2 & 0.0091 & 0.0091 \\
F3 & 0.0091 & 0.033 \\
F4 & 0.0091 & 0.052 \\
F5 & 0.021 & 0.053 \\
F6 & 0.018 & 0.075 \\
M1 & Eq. [9] & 0.0091 \\
M2 & Eq. [9] & 0.0091 \\
M3 & Eq. [9] & 0.021 \\
M4 & Eq. [9] & 0.034 \\
M5 & Eq. [9] & 0.049 \\
M6 & Eq. [9] & 0.072 \\
\hline
\end{tabular}


and dimensionless eddy viscosity, $\lambda$. Eddy viscosity is a coefficient relating the average shear stress within a turbulent flow of water to the vertical gradient of velocity. It actually represents the molecular viscosity and the effects of turbulence from the Reynold's stress terms. Eddy viscosity depends on the momentum of fluid, gradients of the velocity and the scale of flow phenomenon. Knight (1999) pointed out that typical default values of dimensionless eddy viscosity $\lambda$ used within 2-D methods are in the range of $0 \cdot 07-0 \cdot 50$, with standard values being 0.067 (boundary layers), 0.13 (open channels), 0.16 (trapezoidal data), 0.27 (FCF, smooth floodplains), and 0.22 (FCF, rough floodplains). Here, $\lambda$ was set to 0.13 for all applications.

The $\Gamma$ term in the SKM represents the secondary current flows. Omran (2005) and Knight et al (2007) showed that this term has an important role when the focus is on the boundary shear stress distribution across the channel on the zonal discharge. The aim of this paper was to study the overall discharge of the channel, hence the $\Gamma$ term was not considered and $\lambda$ is used as a 'catch all' parameter to represent both lateral shear and secondary flow. This facilitates the modelling approach since default values of, $\lambda$ are adopted and as a result the user has less parameter to deal with.

Ignoring the secondary flow term, the authors applied these three methods to both asymmetric and symmetric compound channel data sets; tests F1 and F2, respectively. The results are shown in figures 3 and 4 . As seen in these figures, Shiono \& Knight method (SKM) and the method of Ervine et al fit each other for each node. Therefore, these two different 2-D methods will be named as LDMs in all figures and tables presented herein as the secondary current term was ignored.

In this paper, the error between the calculated and measured discharge was determined using the following equation:

$$
\operatorname{Error}(\%)=\frac{Q_{c}-Q_{m}}{Q_{m}} \times 100
$$

where $Q_{c}$ is the calculated discharge and $Q_{m}$ is the measured discharge.

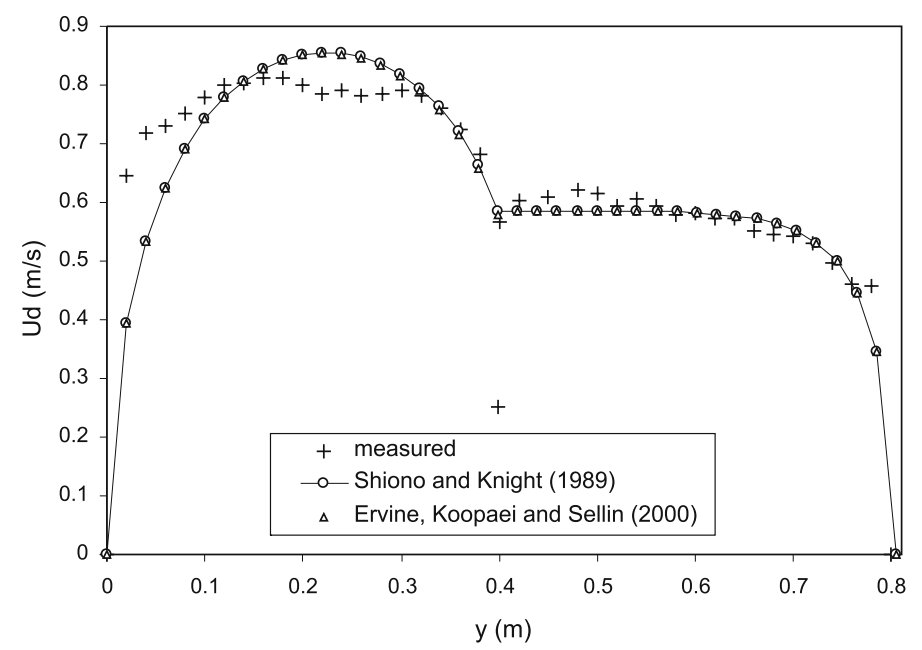

Figure 3. Comparison between analytical and experimental lateral distributions of depth-averaged velocity for test F1 $(H=0.0908 \mathrm{~m}, l=0 \cdot 13, n f p=n m c=0 \cdot 0091)$. 


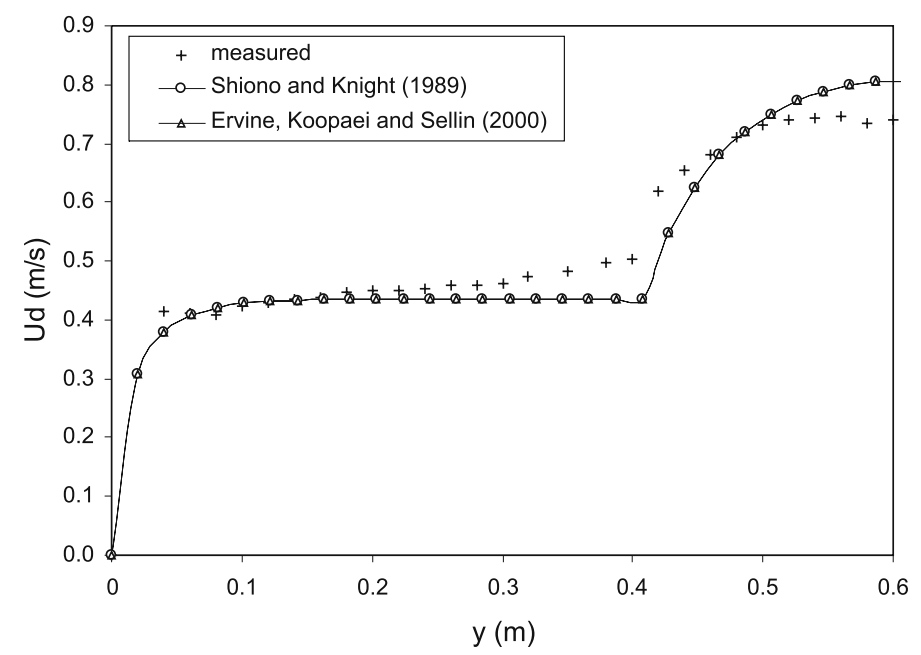

Figure 4. Comparison between analytical and experimental lateral distributions of depth-averaged velocity for test $\mathrm{F} 2(H=0.0761 \mathrm{~m}, l=0.13, n f p=n m c=0.0091)$.

\subsection{Results for smooth main channel and smooth floodplains (tests F1 and F2)}

The stage-discharge results for tests F1 and F2 are shown in figures 5 and 6. Both figures show that the LDMs lie close to the observed values. As expected, DCM overestimates all the measured discharge values for these data sets. It appears in figure 5 that the SCM is also accurate in predicting the discharge for asymmetrical shape of the flume, but its accuracy decreases for low depth ratios for symmetrical shape of the flume, as seen in figure 6 .

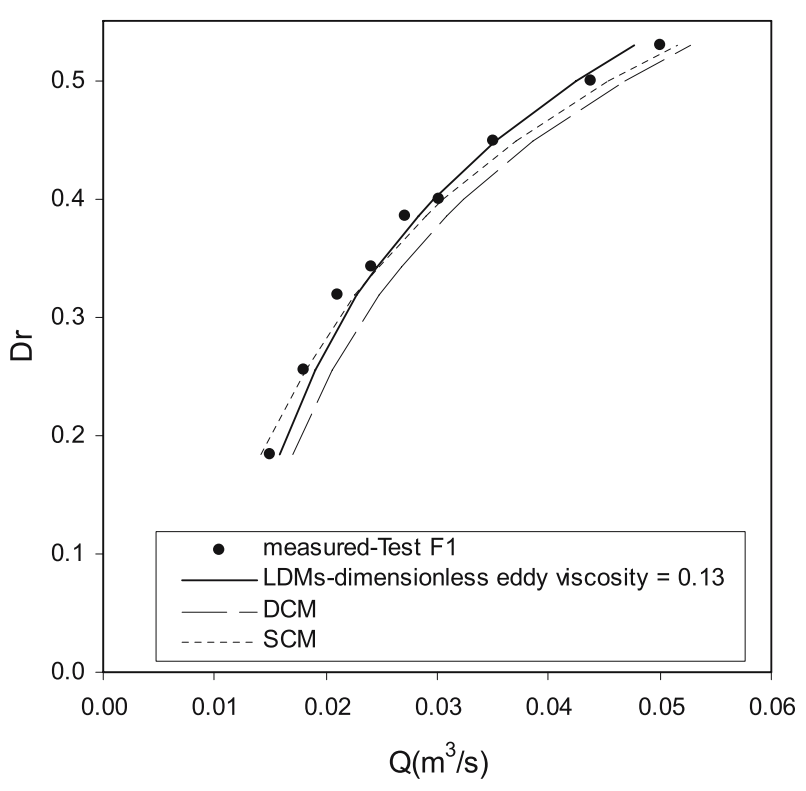

Figure 5. Comparison of the measured data with the estimated stagedischarge curves for test F1. 


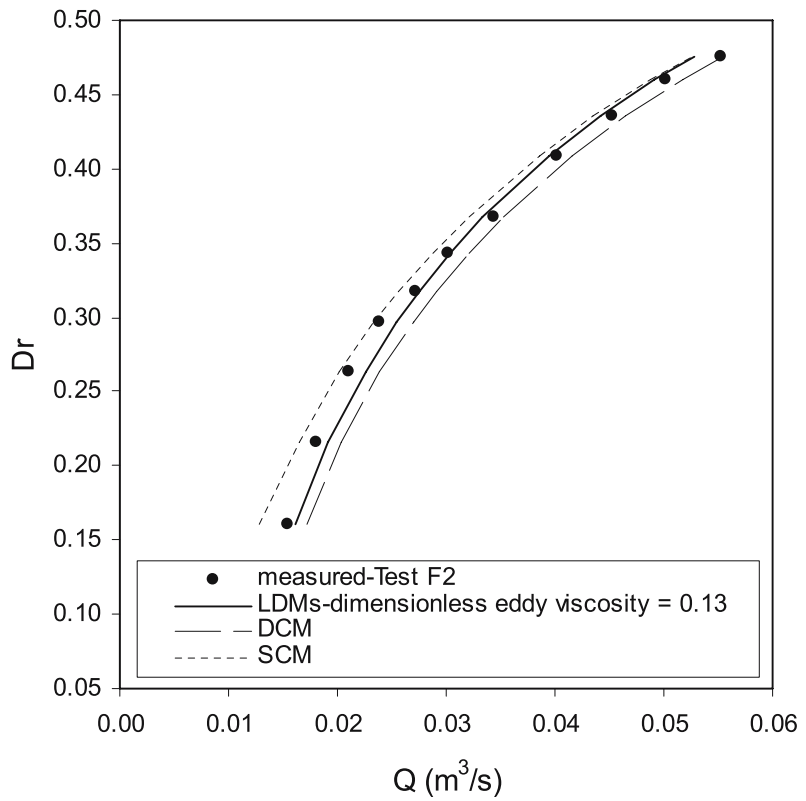

Figure 6. Comparison of the measured data with the estimated stagedischarge curves for test F2.

\subsection{Results for smooth main channel and rough floodplains (tests F3 and F4)}

The results of the predicted and the measured stage-discharge relationship are shown in figures 7 and 8 for the smooth main channel and the different floodplain roughnesses. Although both figures indicate that LDMs predict the measured data well for $\lambda$ value of 0.13 in

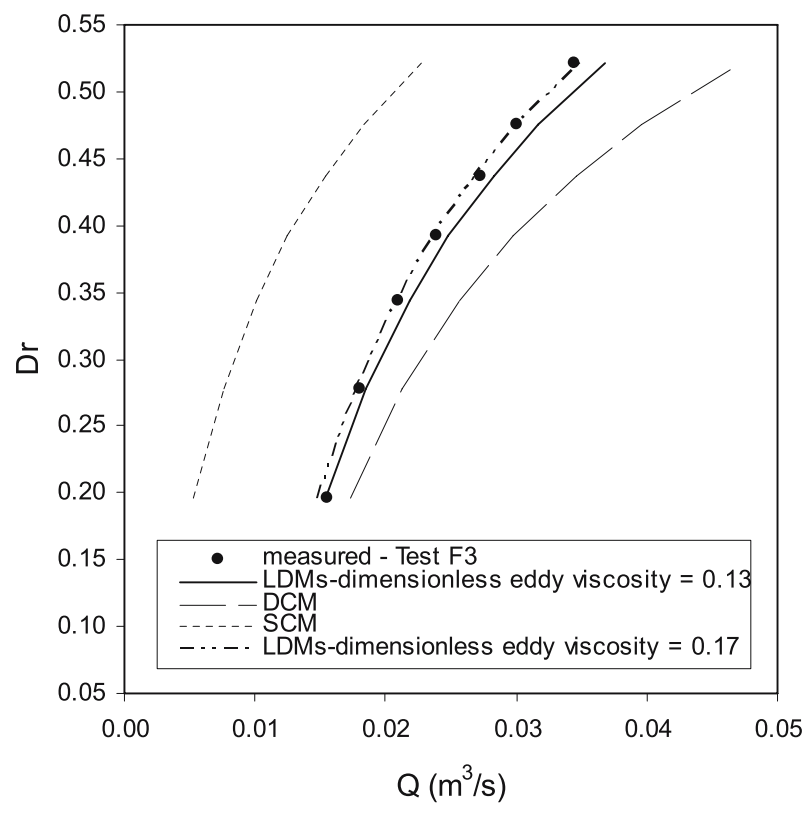

Figure 7. Comparison of the measured data with the estimated stagedischarge curves for test F3. 


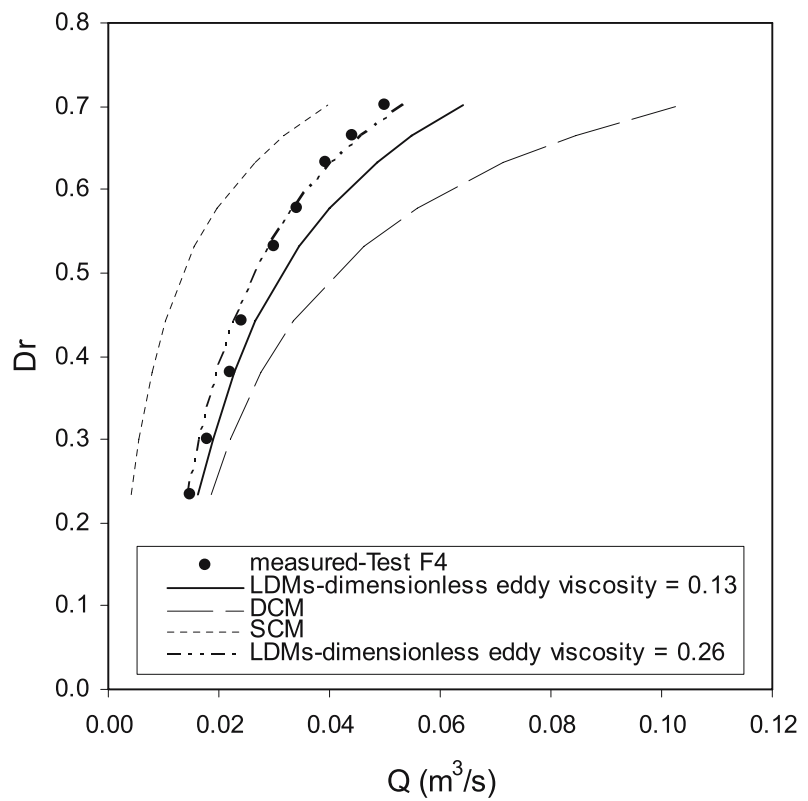

Figure 8. Comparison of the measured data with the estimated stagedischarge curves for test F4.

comparison with the SCM and DCM, the accuracy decreases with increasing depth ratios, especially for test F4. As seen in these figures, the $\lambda$ values of 0.17 and 0.26 , for tests F3 and F4 respectively, which increased the accuracy of the LDMs predictions.

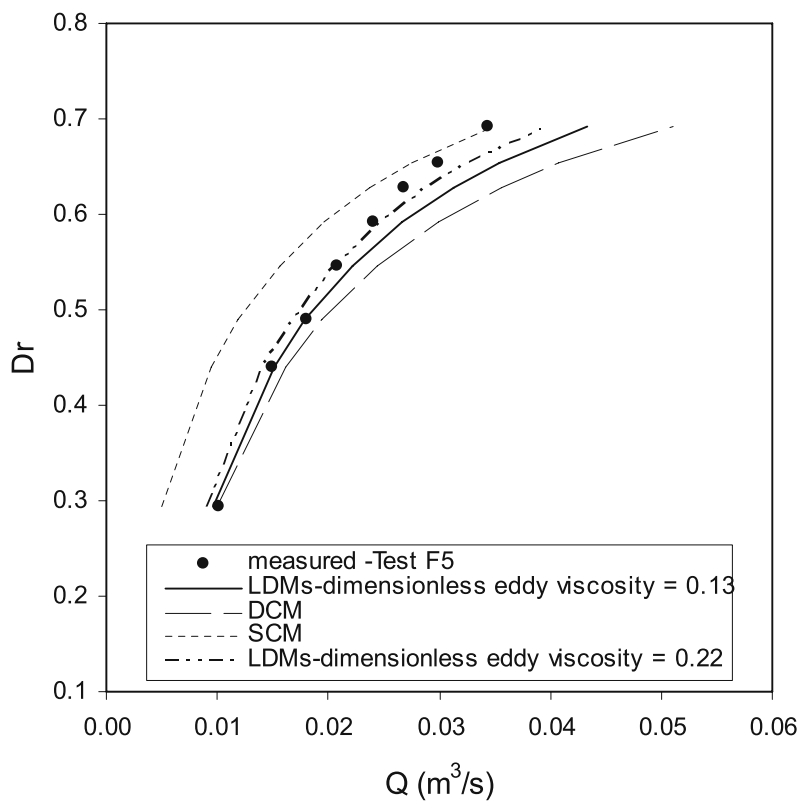

Figure 9. Comparison of the measured data with the estimated stagedischarge curves for test F5. 


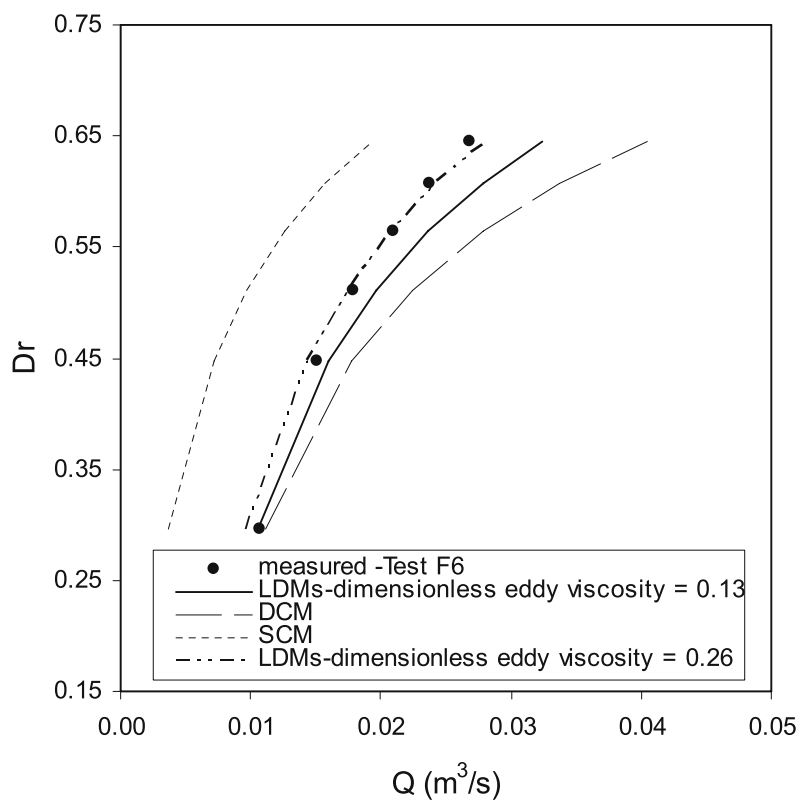

Figure 10. Comparison of the measured data with the estimated stagedischarge curves for test F6.

\subsection{Results for rough main channel and rough floodplains (tests F5 and F6)}

It is well-known that a compound channel behaves like a single channel for $D r>0.5$. Figures 9 and 10 show that LDMs, for the $\lambda$ value of $0 \cdot 13$, give good results up to $D r=0.5$, but deviate from the measured data after that value. It should be highlighted that although the $\lambda$ value of 0.22 decreased the mean error from $9.3 \%$ to $1.7 \%$ for overall data of test F5, it increased the errors for the data lower than $D r=0.5$. Figure 9 also shows that SCM is closer in estimating measured data after $D r=0 \cdot 5$. As seen in figure 10 , the $\lambda$ value of 0.26 increased the accuracy of LDMs predictions for test F6.

\subsection{Results for mobile main channel and smooth floodplains (tests M1 and M2)}

The compound channel configuration of a smooth floodplain adjacent to a mobile main channel represents a situation that is not common in practice, as noted by Cassells et al (2001). Tests M1 and M2 presented here represent this uncommon situation. In this case, estimation of discharge is very problematic, as highlighted by Cassells et al (2001). For Tests M1 and M2, use of the constant Manning's $n$ value for the mobile bed caused large errors up to $20 \%$ in estimation discharge by EDM and COHM (Seckin 2004). Similar errors were also noticed by the Weighted Divided Channel Method (WDCM) developed by Lambert \& Myers (1998) when applied to FCF and the University of Ulster data having a mobile bed and smooth floodplains (See Cassells et al 2001). Atabay \& Knight (2006) showed that COHM gives more accurate results using Manning's $n$ varying with depth $(H)$ for the same data analysed in the current study. Therefore, it is essential to apply 2-D methods to the same University of Birmingham data to compare their performance with the 1-D methods.

As mentioned before, (9) was adopted within all methods analysed here for all mobile boundary cases. The results of the predicted and the measured stage-discharge relationship are shown in figures 11 and 12. As seen in these figures, surprisingly, DCM and SCM produced 


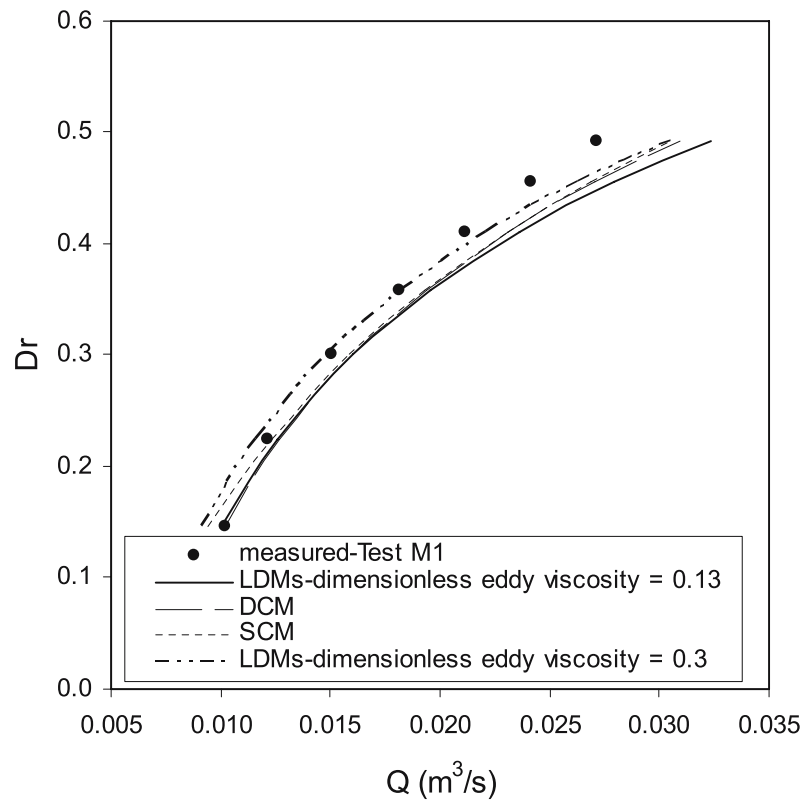

Figure 11. Comparison of the measured data with the estimated stagedischarge curves for test M1.

slightly better predictions than that of the LDMs for high depth ratios. The accuracy of DCM may arise from compensating errors, as highlighted by Cassells et al (2001).

The maximum error produced by LDMs with the $\lambda$ value of 0.13 for test M1 was $19.0 \%$. It decreased to $12.4 \%$ when a $\lambda$ value of 0.3 was used. The $\lambda$ value of 0.3 also decreased the

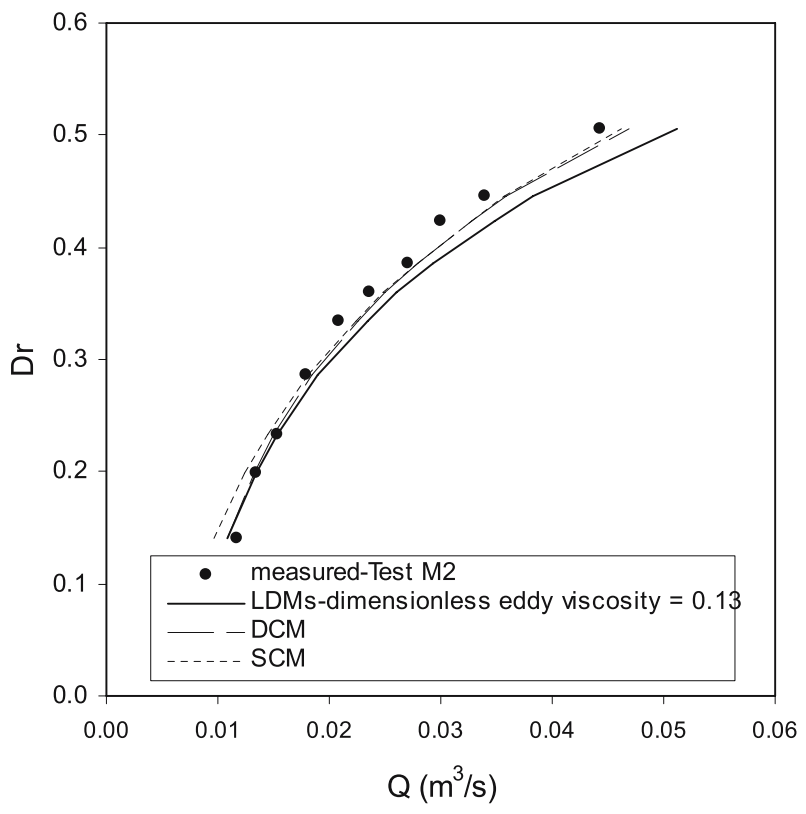

Figure 12. Comparison of the measured data with the estimated stagedischarge curves for test M2. 


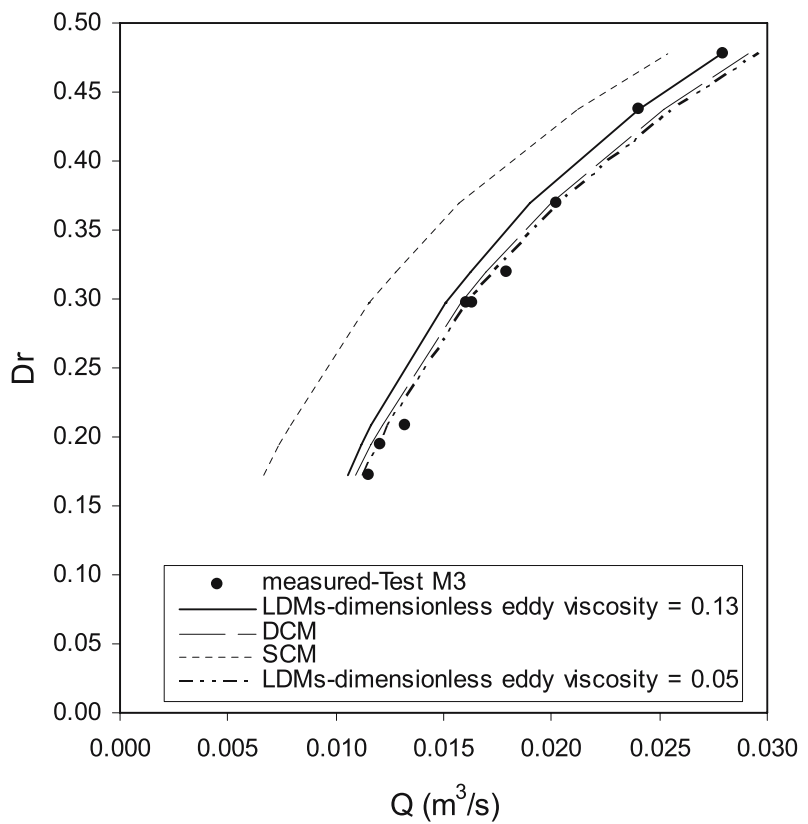

Figure 13. Comparison of the measured data with the estimated stagedischarge curves for test M3.

mean error from $9.05 \%$ to $1.6 \%$. It should be noted that the accuracy of the LDMs would have been increased if different values of $\lambda$ had been used for each depth ratio. For example, for the highest depth ratio $(D r=0.49)$, a $\lambda$ value of 1.0 gives excellent result (e.g. measured

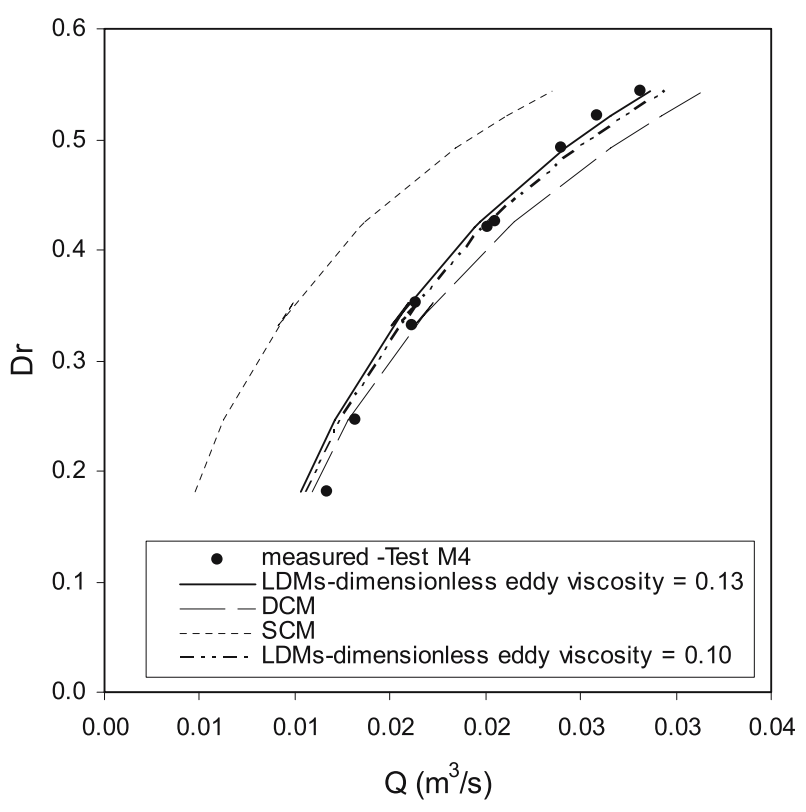

Figure 14. Comparison of the measured data with the estimated stagedischarge curves for test M4. 


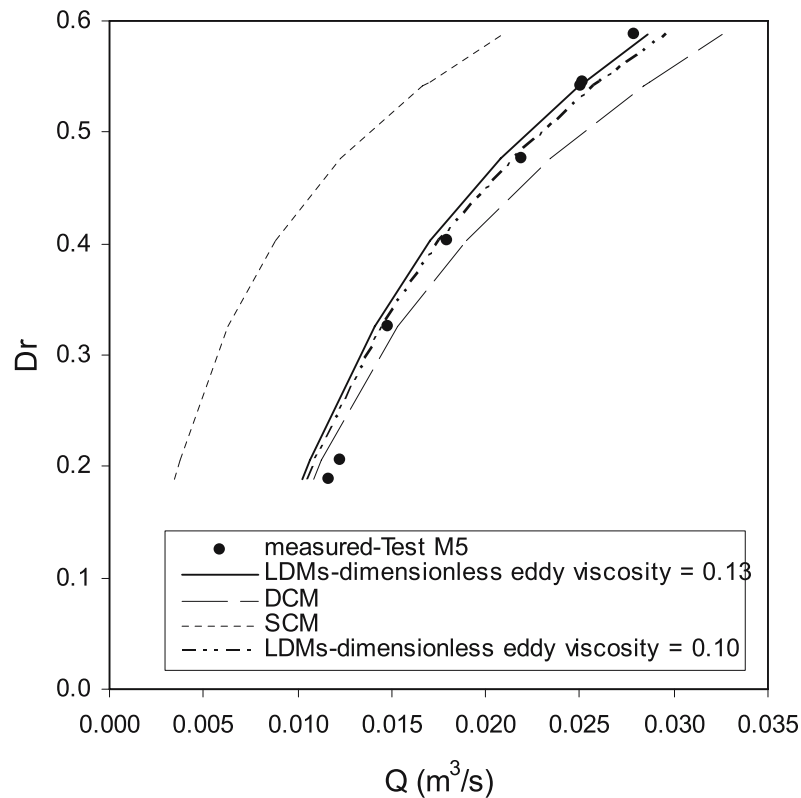

Figure 15. Comparison of the measured data with the estimated stagedischarge curves for test M5.

$Q=0.027 \mathrm{~m}^{3} / \mathrm{s}$ and predicted $Q=0.027 \mathrm{~m}^{3} / \mathrm{s}$ ). However, Knight (1999) pointed out that typical default values of dimensionless eddy viscosity $\lambda$ used within 2-D methods are in the range of $0 \cdot 07-0 \cdot 50$.

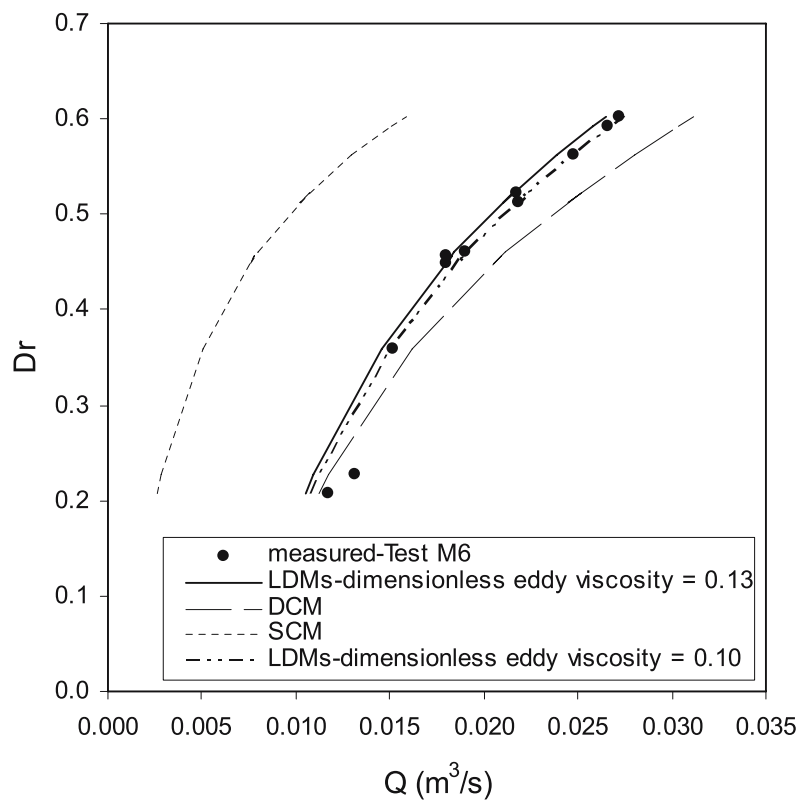

Figure 16. Comparison of the measured data with the estimated stagedischarge curves for test M6. 
Table 4. Prediction errors of each discharge assessment method for fixed beds.

\section{TEST F1}

$\%$ error for each depth ratio

Dr DCM

$\begin{array}{rr}0.18 & 13.5 \\ 0.26 & 14.4 \\ 0.32 & 17.9 \\ 0.34 & 11.5 \\ 0.39 & 14.0 \\ 0.40 & 7.3 \\ 0.45 & 10.3 \\ 0.50 & 6.9 \\ 0.53 & 5.6\end{array}$

\section{TEST F2}

$\%$ error for each depth ratio $\mathrm{Dr}$

DCM

\section{$0 \cdot 16$}

$0 \cdot 22$

0.26

$0 \cdot 30$

$0 \cdot 32$

$0 \cdot 34$

$0 \cdot 37$

0.41

0.44

0.46

0.48

$10 \cdot 5$
$12 \cdot 6$
$14 \cdot 0$
$12 \cdot 8$
$7 \cdot 1$
$6 \cdot 4$
$2 \cdot 6$
$3 \cdot 6$
$2 \cdot 8$
$3 \cdot 0$
$0 \cdot 2$

TEST F3

$\%$ error for each depth ratio Dr

$$
\text { DCM }
$$

$0 \cdot 20$

$0 \cdot 28$

0.34

$0 \cdot 39$

0.44

0.48

0.52

$15 \cdot 7$
$18 \cdot 0$
$22 \cdot 2$
$23 \cdot 5$
$28 \cdot 0$
$32 \cdot 1$
$37 \cdot 5$

TEST F4

$\%$ error for each depth ratio

\begin{tabular}{|c|c|c|c|c|}
\hline Dr & DCM & SCM & LDMs & LDMs (calibrated) \\
\hline 0.23 & $25 \cdot 6$ & $-72 \cdot 1$ & $10 \cdot 4$ & $-2 \cdot 5$ \\
\hline 0.30 & $22 \cdot 2$ & -69.4 & 43.7 & $-8 \cdot 5$ \\
\hline 0.38 & $25 \cdot 8$ & -64.4 & $3 \cdot 8$ & $-10 \cdot 4$ \\
\hline 0.44 & 39.1 & $-57 \cdot 3$ & $10 \cdot 8$ & $-5 \cdot 3$ \\
\hline 0.53 & 53.6 & -47.9 & 14.9 & $-3 \cdot 2$ \\
\hline 0.58 & 62.7 & -42.4 & $16 \cdot 8$ & $-2 \cdot 2$ \\
\hline 0.63 & 82.0 & -32.8 & 23.4 & 2.9 \\
\hline 0.67 & $90 \cdot 9$ & -28.0 & 24.4 & $3 \cdot 6$ \\
\hline 0.70 & 106.5 & -20.7 & 28.0 & $6 \cdot 6$ \\
\hline
\end{tabular}

SCM LDMs LDMs (calibrated)

SCM LDMs LDMs (calibrated)

$-17 \cdot 0$

3.7

5.9

$7 \cdot 4$

6.4

$1 \cdot 2$ no calibration

$\begin{array}{rr}-4.7 & 0 \cdot 6 \\ -6.8 & -2.9\end{array}$

$-4.1 \quad-1.8$

$\begin{array}{ll}-3.9 & -2.4\end{array}$

$-2.8 \quad-2 \cdot 1$

$-5.0 \quad-4.7$
$-5 \cdot 6 \quad 1 \cdot 2$

SCM LDMs LDMs (calibrated)

$-64 \cdot 3 \quad-0 \cdot 5$

$-57 \cdot 8$

$-51 \cdot 7$

$-4 \cdot 3$

$-2 \cdot 0$

$-0.7$

$-1 \cdot 0$

$-1 \cdot 3$

$-43 \cdot 2$

$-39 \cdot 0$

$-33.7$

0.0

6.9

1.2

3.9

$3 \cdot 8$
$5 \cdot 4$

.


Table 4. (Continued).

\begin{tabular}{|c|c|c|c|c|}
\hline \multicolumn{5}{|c|}{$\begin{array}{l}\text { TEST F5 } \\
\% \text { error for each depth ratio }\end{array}$} \\
\hline $\mathrm{Dr}$ & $\mathrm{DCM}$ & $\mathrm{SCM}$ & LDMs & LDMs (calibrated) \\
\hline $\begin{array}{l}0.29 \\
0.44 \\
0.49 \\
0.55 \\
0.59 \\
0.63 \\
0.65 \\
0.69\end{array}$ & $\begin{array}{r}-1.7 \\
7.4 \\
7 \cdot 8 \\
17 \cdot 3 \\
24.7 \\
33 \cdot 0 \\
36 \cdot 8 \\
48.9\end{array}$ & $\begin{array}{r}-51.3 \\
-37.1 \\
-34.0 \\
-25.2 \\
-18.4 \\
-11.4 \\
-7.8 \\
1.7\end{array}$ & $\begin{array}{r}-5.1 \\
0.5 \\
-0.4 \\
6.5 \\
11.3 \\
16.8 \\
18.6 \\
26.3\end{array}$ & $\begin{array}{r}-10 \cdot 0 \\
-5.6 \\
-6 \cdot 8 \\
-0.9 \\
3 \cdot 2 \\
8 \cdot 0 \\
9.4 \\
16 \cdot 2\end{array}$ \\
\hline \multicolumn{5}{|c|}{$\begin{array}{l}\text { TEST F6 } \\
\% \text { error for each depth ratio }\end{array}$} \\
\hline $\begin{array}{l}0.30 \\
0.45 \\
0.51 \\
0.56 \\
0.61 \\
0.64\end{array}$ & $\begin{array}{r}5 \cdot 0 \\
17 \cdot 3 \\
26 \cdot 0 \\
32 \cdot 9 \\
41 \cdot 4 \\
51 \cdot 0\end{array}$ & $\begin{array}{l}-65.5 \\
-52.7 \\
-45.7 \\
-40.0 \\
-34.1 \\
-27.9\end{array}$ & $\begin{array}{r}-1 \cdot 1 \\
5 \cdot 3 \\
9 \cdot 9 \\
12 \cdot 7 \\
16 \cdot 7 \\
21 \cdot 0\end{array}$ & $\begin{array}{r}-9.5 \\
-5.6 \\
-2.5 \\
-1.0 \\
1.8 \\
5.0\end{array}$ \\
\hline
\end{tabular}

The maximum and mean error produced by LDMs with the $\lambda$ value of 0.13 for test M2 were $16.0 \%$ and $7.5 \%$, respectively. For test M2, some attempts were also made to calibrate $\lambda$, but no significant improvement was achieved as discussed above.

\subsection{Results for mobile main channel and rough floodplains (tests M3, M4, M5 and M6)}

The effect of various densities of $A$-frames of aluminum wire grids on the floodplain is shown in figures 13, 14, 15 and 16 for tests M3, M4, M5 and M6, respectively. As seen in these figures, the accuracy of the LDMs using the $\lambda$ value of 0.13 improves better with increasing densities of $A$-frames. Using the calibrated values of $\lambda, 0.05$ for test M3 and 0.1 for tests 14-16, respectively, LDMs give more accurate results. As seen in these figures, SCM almost underpredicted the measured data for these series in contrast to DCM.

Prediction errors of each method, namely DCM, SCM and LDMs, are shown in tables 4 and 5 for fixed and mobile boundary cases, respectively.

\section{Conclusions}

The following conclusions may be drawn from this study:

For fixed boundary cases;

(i) For smooth surfaces, LDMs, with the $\lambda$ value of $0 \cdot 13$, gave slightly more accurate predictions than the SCM and DCM, and no calibration of $\lambda$ was needed.

(ii) For roughened surfaces, although LDMs, with the $\lambda$ value of $0 \cdot 13$, predict the data sufficiently accurately for depth ratios lower than $0 \cdot 5$, there were excellent correlations between the measured values and predictions, when the $\lambda$ value was calibrated. SCM 
Table 5. Prediction errors of each discharge assessment method for mobile beds.

\section{TEST M1}

$\%$ error for each depth ratio

Dr DCM

$0 \cdot 15$

0.22

$0 \cdot 30$

$0 \cdot 36$

0.41

0.46

0.49

$$
0 \cdot 0
$$

4.4

6.0

6.8

9.3

$12 \cdot 1$

13.9

\section{TEST M2}

$\%$ error for each depth ratio

Dr DCM

$\begin{array}{rr}0.14 & -8 \cdot 2 \\ 0 \cdot 20 & -1 \cdot 8 \\ 0 \cdot 23 & -1 \cdot 3 \\ 0.29 & 3.4 \\ 0.34 & 7 \cdot 8 \\ 0.36 & 5 \cdot 5 \\ 0.39 & 3 \cdot 3 \\ 0.42 & 9 \cdot 0 \\ 0.45 & 5 \cdot 3 \\ 0.51 & 5 \cdot 5\end{array}$

\section{TEST M3}

$\%$ error for each depth ratio

Dr DCM

$\begin{array}{rr}0 \cdot 17 & -5 \cdot 2 \\ 0 \cdot 19 & -3 \cdot 7 \\ 0 \cdot 21 & -8 \cdot 0 \\ 0 \cdot 30 & -1 \cdot 8 \\ 0 \cdot 30 & -3 \cdot 3 \\ 0 \cdot 32 & -5 \cdot 4 \\ 0 \cdot 37 & -1 \cdot 4 \\ 0 \cdot 44 & 5 \cdot 0 \\ 0.48 & 4 \cdot 0\end{array}$

TEST M4

$\%$ error for each depth ratio Dr

$$
\text { DCM }
$$

$0 \cdot 18$

$0 \cdot 25$

0.33

0.35

0.42

0.43

0.49

0.52

0.54
LDMs

$-1 \cdot 3$

$3 \cdot 8$

$6 \cdot 3$

$8 \cdot 1$

11.6

$15 \cdot 8$

$19 \cdot 0$
LDMs

$-8.0$

$-0.6$

0.6

6.4

$12 \cdot 1$

$10 \cdot 4$

8.8

$16 \cdot 0$

$12 \cdot 7$

$15 \cdot 3$
LDMs (calibrated)

$$
\begin{array}{r}
-9.6 \\
-4.4 \\
-1.5 \\
0.7 \\
4.5 \\
8.9 \\
12.4
\end{array}
$$

LDMs (calibrated)

$$
\text { no calibration }
$$

\section{LDMs}

LDMs (calibrated)

$-8.6$

$-7 \cdot 3$

$-11.6$

$-6 \cdot 2$

$-7.6$

$-9.7$

$-6 \cdot 1$

0.1

$-0 \cdot 5$

$$
\begin{array}{r}
-2.5 \\
-1 \cdot 0 \\
-5 \cdot 5 \\
0 \cdot 2 \\
-1 \cdot 3 \\
-3 \cdot 5 \\
0 \cdot 3 \\
6 \cdot 8 \\
6 \cdot 0
\end{array}
$$

LDMs

LDMs (calibrated)

$-11.7$

$-8 \cdot 1$

$-6 \cdot 3$

$-2 \cdot 6$

$-3 \cdot 5$

$-4 \cdot 2$

0.8

2.7

2.7
1.6

$$
\begin{array}{r}
-9.5 \\
-5 \cdot 8 \\
-3 \cdot 8 \\
0.1 \\
-0.7 \\
-1.5 \\
3.7 \\
5 \cdot 6 \\
4.5
\end{array}
$$


Table 5. (Continued).

\begin{tabular}{|c|c|c|c|c|}
\hline \multicolumn{5}{|c|}{$\begin{array}{l}\text { TEST M5 } \\
\% \text { error for each depth ratio }\end{array}$} \\
\hline $\mathrm{Dr}$ & DCM & SCM & LDMs & LDMs (calibrated) \\
\hline $\begin{array}{l}0.19 \\
0.21 \\
0.33 \\
0.40 \\
0.48 \\
0.54 \\
0.55 \\
0.59\end{array}$ & $\begin{array}{r}-3 \cdot 9 \\
-2 \cdot 9 \\
4 \cdot 5 \\
9 \cdot 5 \\
14 \cdot 2 \\
17 \cdot 9 \\
18 \cdot 1 \\
20 \cdot 0\end{array}$ & $\begin{array}{l}-69 \cdot 2 \\
-67 \cdot 8 \\
-57 \cdot 0 \\
-49 \cdot 0 \\
-40 \cdot 0 \\
-30 \cdot 8 \\
-30 \cdot 1 \\
-23 \cdot 1\end{array}$ & $\begin{array}{r}-11.7 \\
-12.9 \\
-5.0 \\
-5.0 \\
-5.0 \\
-0.4 \\
0.2 \\
2.6\end{array}$ & $\begin{array}{r}-9.5 \\
-10.7 \\
-2.3 \\
-2.0 \\
-1.8 \\
3.1 \\
3.7 \\
6.1\end{array}$ \\
\hline \multicolumn{5}{|c|}{$\begin{array}{l}\text { TEST M6 } \\
\% \text { error for each depth ratio }\end{array}$} \\
\hline $\begin{array}{l}\text { Dr } \\
0.21 \\
0.23 \\
0.36 \\
0.45 \\
0.46 \\
0.46 \\
0.52 \\
0.51 \\
0.56 \\
0.59 \\
0.60\end{array}$ & $\begin{array}{r}\text { DCM } \\
-4 \cdot 5 \\
-11 \cdot 0 \\
6 \cdot 8 \\
13 \cdot 8 \\
16 \cdot 0 \\
10 \cdot 9 \\
15 \cdot 3 \\
11 \cdot 9 \\
13 \cdot 2 \\
13 \cdot 9 \\
14 \cdot 8\end{array}$ & $\begin{array}{l}\text { SCM } \\
-77 \cdot 5 \\
-78 \cdot 2 \\
-66 \cdot 4 \\
-57 \cdot 9 \\
-56 \cdot 6 \\
-58 \cdot 2 \\
-50 \cdot 9 \\
-53 \cdot 3 \\
-47 \cdot 5 \\
-43 \cdot 4 \\
-41 \cdot 6\end{array}$ & $\begin{array}{r}\text { LDMS } \\
-10 \cdot 4 \\
-16 \cdot 9 \\
-3 \cdot 8 \\
-0 \cdot 3 \\
1 \cdot 4 \\
-3 \cdot 2 \\
-1 \cdot 0 \\
-3 \cdot 8 \\
-3 \cdot 6 \\
-3 \cdot 3 \\
-2 \cdot 6\end{array}$ & $\begin{array}{c}\text { LDMs (calibrated) } \\
-8 \cdot 1 \\
-14 \cdot 7 \\
-0 \cdot 8 \\
3 \cdot 3 \\
5 \cdot 1 \\
0 \cdot 4 \\
2 \cdot 8 \\
-0 \cdot 1 \\
0 \cdot 2 \\
0 \cdot 5 \\
1 \cdot 2\end{array}$ \\
\hline
\end{tabular}

consistently underpredicted and the DCM overpredicted the measured data for each case of roughened surfaces.

(iii) For fixed bed data, the average errors for each method were $25.2 \%, 24.2 \%$ and $\mathbf{6 . 6} \%$ for SCM, DCM and LDMs ( $\lambda$ value of 0.13 ) respectively and the average error was $\mathbf{0 . 3} \%$ for LDMs with the calibrated values of $\lambda$.

For mobile boundary cases;

(i) For mobile main channel and smooth floodplain cases, the modelling of the stage discharge relationship still remains as problematic as discussed by Cassells et al (2001), Seckin (2004), and Atabay \& Knight (2006). LDMs, with the $\lambda$ value of $0 \cdot 3$, produced more accurate results than those of SCM and DCM for asymmetrical case. LDMs failed for the symmetrical case for high depth ratios in comparison with the SCM and DCM. However, LDMs would have produced better results if the varying values of $\lambda$ for the same data sets had been used. However, in this case, the values of $\lambda$ would not have been in the range of its typical default values.

(ii) For mobile main channel and rough floodplain cases, the LDMs, with the $\lambda$ value of $0 \cdot 13$, still gave more accurate results than that of SCM and DCM for most of the cases. However, the accuracy of them was highly increased with the calibrated $\lambda$ values. SCM consistently underpredicted the measured data for each case. The accuracy of DCM decreased with increasing densities of roughness elements. 
(iii) For mobile bed data, the average errors for each method were $\mathbf{2 8 . 3} \%, \mathbf{5 . 2} \%$ and $\mathbf{- 0 . 7} \%$ for SCM, DCM and LDMs (with $\lambda$ value of $0 \cdot 13$ ). The average error was $\mathbf{1 . 0} \%$ for LDMs with the calibrated values of $\lambda$.

For overall data (104 measured data points), the average errors for each method were LDMs, with $\lambda$ value of $0 \cdot 13, \mathbf{2} .8 \%$, DCM 14.3\% and SCM-26.8\%. The average error was $\mathbf{0 . 5} \%$ for LDMs with the calibrated values of $\lambda$.

The authors are grateful to Geoff Denham, for his invaluable comments in improving this paper and for his proof reading.

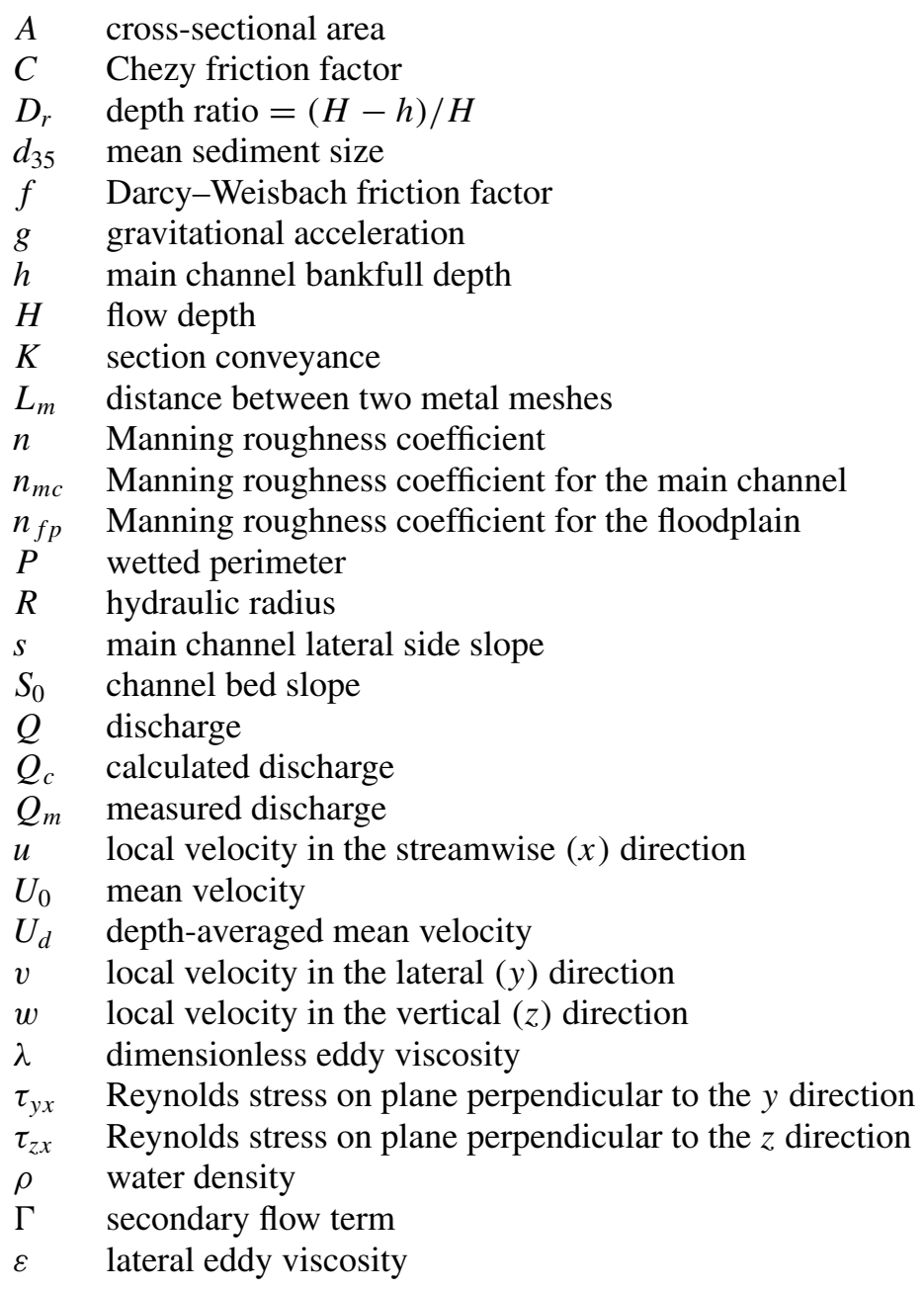

\section{References}

Ackers P 1993 Flow formulae for straight two-stage channels. J. Hydraulic Res. 31(4): 509-531 
Atabay S 2001 Stage-discharge, resistance and sediment transport relationships for flow in straight compound channels. PhD thesis, The University of Birmingham, England, U.K

Atabay S, Knight D W 1999 Stage discharge and resistance relationships for laboratory alluvial channels with overbank flow. Proc. of the 7th International Symposium on River Sedimentation, Hong Kong : 223-229

Atabay S, Knight D W, Seckin G 2004 Influence of a mobile bed on the boundary shear in a compound channel. Proc. Int. Conf. on Fluvial Hydraulics, River Flow, Naples, Italia Vol. I: 337-345

Atabay S, Knight D W, Seckin G 2005 The effects of overbank flow on fluvial sediment transport rates. Proc. of the Institution of Civil Engineers, Water Management 158(1): 25-34

Atabay S, Knight D W 2006 1-D modelling of conveyance, boundary shear and sediment transport in overbank flow. J. Hydraulic Res. 44(6): 739-754

Atabay S, Seckin G 2000 Comparison of sediment transport rates between symmetric and asymmetric straight compound channels. Proc. of the 8th International Symposium on Stochastic Hydraulics, China : 139-144

Ayyoubzadeh S A 1997 Hydraulic aspects of straight compound channel flow and bedload sediment transport. $\mathrm{PhD}$ thesis, The University of Birmingham, England, U.K

Bousmar D, Zech Y 1999 Momentum transfer for practical flow computation in compound channels. J. Hydraulic Eng. American Society of Civil Engineers 125: 696-706

Cassells J B C, Lambert M F, Myers R W C 2001 Discharge prediction in straight mobile bed compound channels. Proc. of the Institution of Civil Engineers, Water \& Maritime Engineering 148(3): $177-188$

Ervine D A, Babaeyan-Koopaei K, Sellin R H J 2000 Two-dimensional solution for straight and meandering overbank flows. J. Hydraulic Eng. 126: 653-669

Knight D W, Demetriou J D 1983 Floodplain and main channel flow interaction. J. Hydraulic Eng. 109: 1073-1092

Knight D W, Hamed M E 1984 Boundary shear in symmetrical compound channel. J. Hydraulic Eng. ASCE 110(10): 1412-1430

Knight D W 1999 Flow mechanisms and sediment transport in compound channels. Int. J. Sediment Res. 14(2): 217-236

Knight D W, Brown F A, Ayyoubzadeh S A, Atabay S 1999 Sediment transport in river models with overbank flow. Proc. of 7th International Symposium on River Sedimentation, Hong Kong : $19-25$

Knight D W, Omran M, Tang X 2007 Modelling depth-averaged velocity and boundary shear in trapezoidal channels with secondary flows. J. Hydraulic Eng. ASCE 133(1): 39-47

Lambert M F and Sellin R H J 1996 Discharge prediction in straight compound channels using the mixing length concept. J. Hydraulic Res. 34: 381-394

Lambert M F, Myers W R C 1998 Estimating the discharge capacity of straight compound channels. Proc. Inst. Civil Engineers, Water and Maritime Eng. 130(2): 84-94

Myers W R C and Elsawy E M 1975 Boundary shear in channel with floodplain. J. Hydraulics Res. 101: 933-946

Myers W R C 1978 Momentum transfer in a compound channel. J. Hydraulic Res. 16: 139-150

Myers W R C, Lyness J F, Cassells J 2001 Influence of boundary roughness on velocity and discharge in compound river channels. J. Hydraulic Res. 39: 311-319

Omran M 2005 Modelling stage-discharge curves, velocity and boundary shear stress distributions in natural and artificial channels using a depth-averaged approach. $\mathrm{PhD}$ Thesis, The University of Birmingham, England, UK

Prinos P, Townsend R D 1984 Comparison of methods for predicting discharge in compound open channels. Advances in Water Resources 7: 180-187

Prooijen B C, Battjes J A, Uijttewaal W S 2005 Momentum exchange in straight uniform compound channel flow. J. Hydraulic Eng. 131: 175-183

Seckin G 2004 A comparison of one-dimensional methods for estimating discharge capacity of straight compound channels. Canad. J. Civil Eng. 31: 619-631 
Seckin G, Atabay S 2005 Experimental backwater analysis around bridge waterways. Canad. Civil Eng. 32(6): 1015-1029

Sellin R H J 1964 A laboratory investigation into the interaction between flow in the channel of a river and that of its floodplain. La Houille Blanche 7: 793-801

Shiono K, Knight D W 1989 Two dimensional analytical solution compound channel. Proc. of $3^{\text {rd }}$ Int. Symp. on refined flow modelling and turbulence measurements, Universal Academy Press : 591-599

Shiono K, Knight D W 1991 Turbulent open channel flows with variable depth across the channel. J. Fluid Mech. Cambridge, U.K. 222: 617-646

Tang X, Knight D W 2001 Experimental study of stage-discharge relationships and sediment transport rates in a compound channel. Proc. of 29th IAHR Congress, Beijing, China : 69-76

Tang X 2002 Flow roughness of wire mesh (unpublished report, No. 7), Birmingham University

Tang X, Knight D W 2006 Sediment transport in river models with overbank flows. J. Hydraulic Eng. 132(1): 77-86

Wark J B, Samuels P G, Ervine D A 1990 A practical method of estimating velocity and discharge in compound channels. Proc. of the International Conference On River Flood Hydraulics (U.K: Wiley) $163-172$

Wormleaton P R, Allen J, Hadjipanos P 1982 Discharge assessment in compound channel flow. J. Hydraulics Res. American Society of Civil Engineers 108: 975-994

Wormleaton P R, Hadjipanos P 1985 Flow distribution in compound channels. J. Hydraulic Res. American Society of Civil Engineers 111: 357-361

Wright R R, Carstens H R 1970 Linear momentum flux to overbank sections. J. Hydraulics Res. American Society of Civil Engineers 96: 1781-1793

Zheleznyakov G V 1971 Interaction of channel and flood plain flows. Proc. of the 14th International Conference of the International Association for Hydraulic Research, Paris : 144-148 